\title{
Rosin Product Review
}

\author{
Vidhura Mahendra1, $\mathrm{a}^{*}$ \\ ${ }^{1}$ Centre for Rapid and Sustainable Product Development, Polytechnic Institute of Leiria, \\ Edificio IPL, Rua de Portugal - Zona Industrial, 2430-028 - Marinha Grande, Portugal \\ avidhura.mahendra@ipleiria.pt
}

Keywords: rosin, rosin acid, rosin composites, epoxy binders, material properties, biomedical applications, advanced material

\begin{abstract}
Rosin is the non-volatile exudate of pine resin with hydrophobic characteristics that are widely used and modified as a precursor for many industrial applications such as paints, inks and adhesives. The review paper discusses the rosin, its nature, processing, production material development for green science. The composite materials have been designed and tailored with respect to desired applications to offer a potential replacement of petrochemical use. Rosin consists of different resin acids that can undergo isomerisation at elevated temperatures and interchange its form, which, can be used as a rigid building block to manipulate their mechanical properties and crystallisation behaviours. Modified rosin epoxy binders have been recognised as materials with resistance to a wide variety of chemical conditions that can be used to fabricate a variety of reinforced constructions. Rosin has been employed in foam making in addition to composite material, depicting its ability as a crosslinker.
\end{abstract}

\section{Introduction}

Rosins are the solid form of resins obtained from pines or similar types of plants belonging to the conifer family. It is produced by heating the liquid resin to vaporize the volatile liquid terpenes which are large group of unsaturated hydrocarbons. Rosin is semi-transparent and varies in colour from pale yellow to black. The crude pine resin isolated by tapping the tree approximately contains $70 \%$ rosin, $15 \%$ turpentine and $15 \%$ debris and water [1]. At room temperature rosin is brittle and softens at higher temperatures. Rosin [2] chiefly consists of different resin acids, especially abietic, pimaric acid and are not polymers like hydrocarbon resins but a blend of molecules characterised by three fused six-carbon rings, double bonds that vary in number, location and a single carboxylic acid group as in Figure 1. The ratio of these isomers depends on the collection method and the species of the tree from which the rosin is produced. The molecular weight of the rosin is quite different compared with hydrocarbon resins. Rosin is classified into three main types; gum rosin, wood rosin and tall rosin. Gum rosin as shown in Figure 2, collected from the tree is the most common type obtained by tapping the living pine tree [3]. Soap manufacture, paper sizing, printing inks, surface coatings, adhesives [4] and rubber additives are some of the primary applications associate with rosin. Moreover, in this article we aim to look into rosin composite materials and their applications via advanced science and technology.

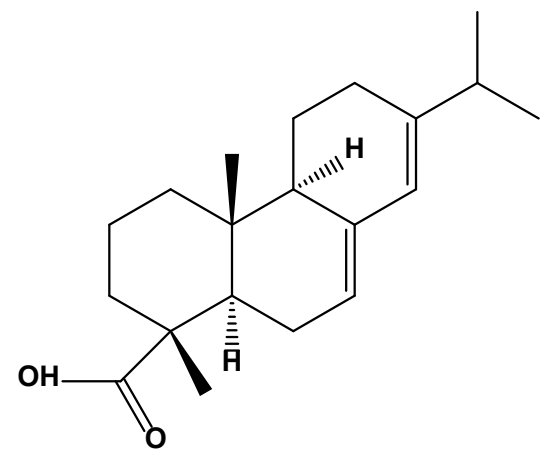

Fig. 1: Structure of a rosin acid isomer - abietic acid 


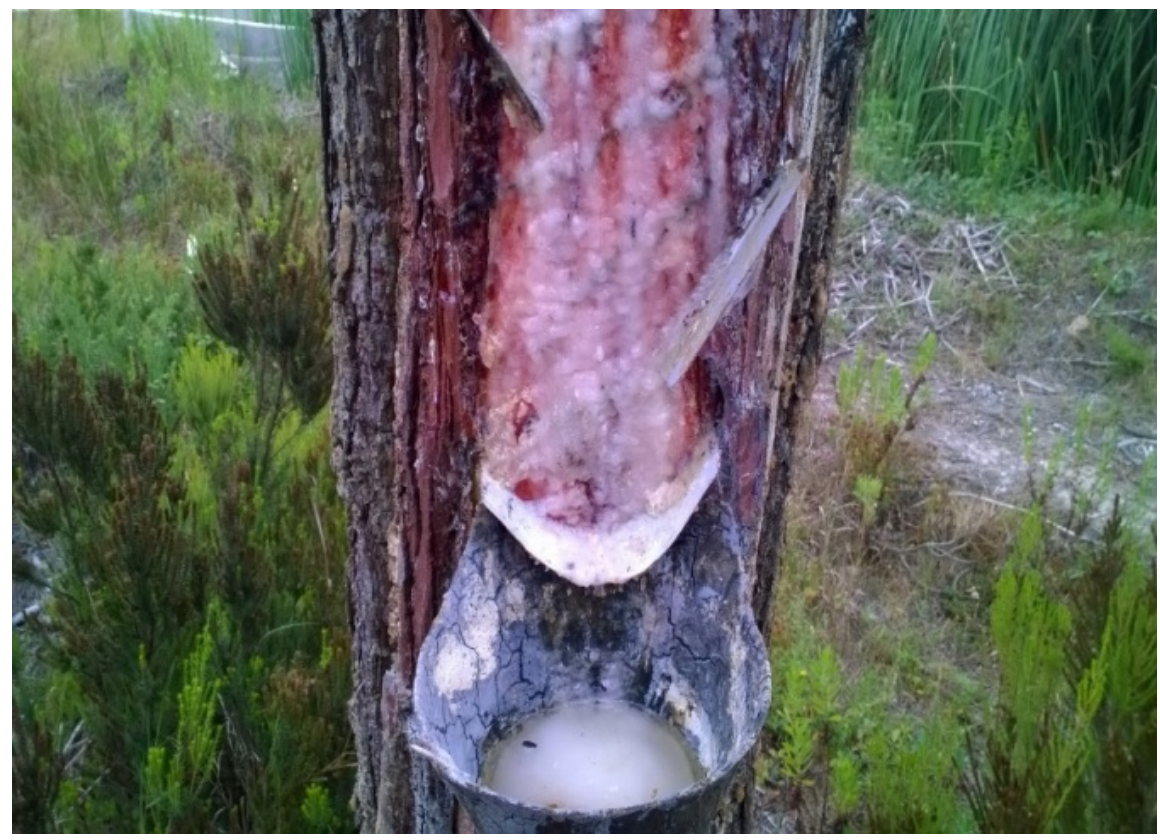

Fig. 2: Pine resins collected from the tree

Rosin acids contain a free carboxyl group and carbon-carbon double bonds, readily react with other reagents to achieve various intermediates. Such reaction intermediates can be employed for various linkages in industrial and biomedical applications. European Rosin market by applications Gum Rosin + Tall-Oil Rosin $=325.000$ MT (Source: PCA International Conference, Boston September 2012) [5] is shown in Figure 3.

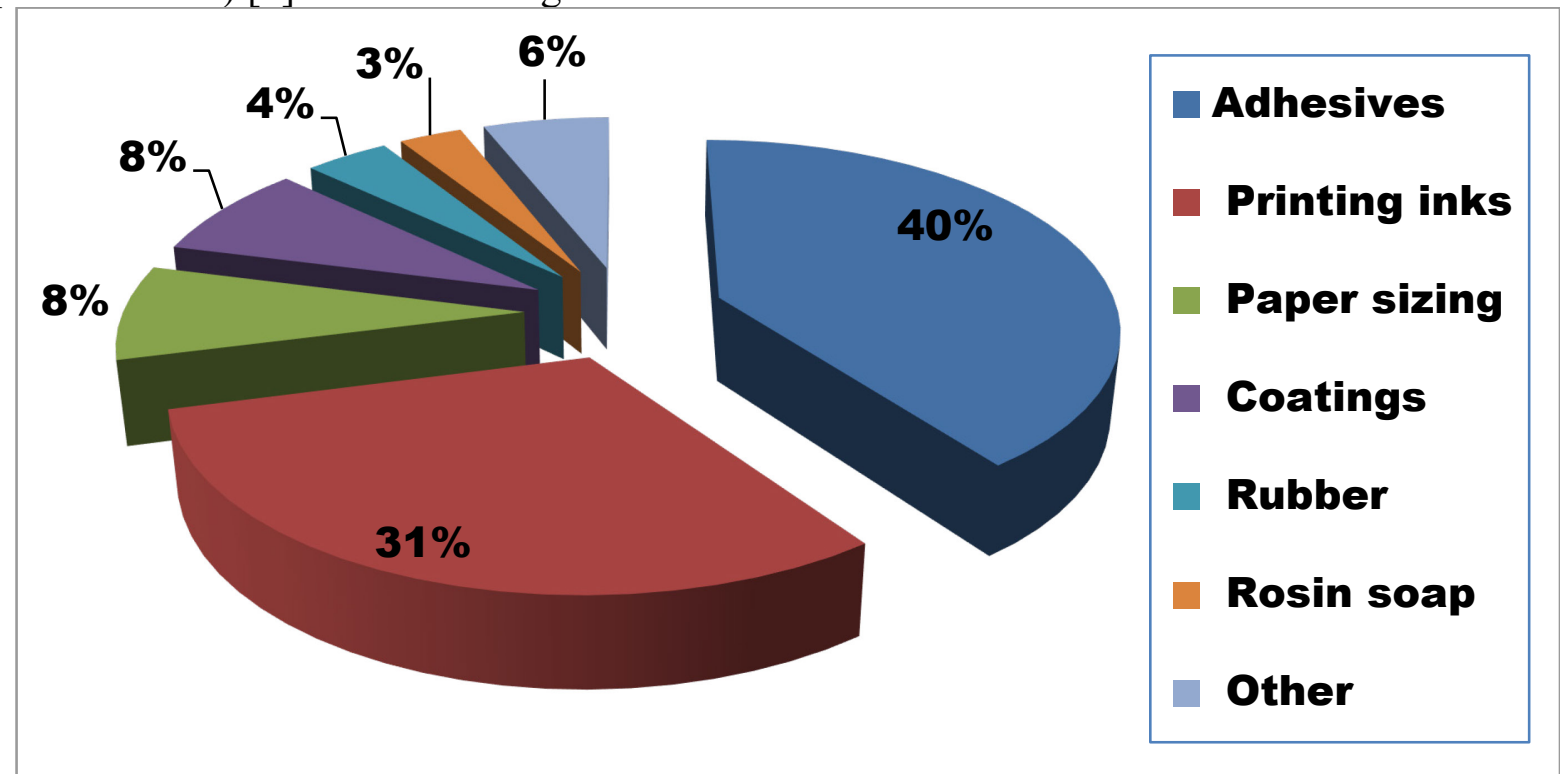

Fig. 3: European rosin market by applications [6]

Rosin production methods. Gum rosin and gum spirit of turpentine are acquired by tapping the bark of the pine tree [7] and gathering the oleoresin which exudes, in a suitable cup as shown in the Figure 2. The oleoresin is a viscous semi-crystalline mass contaminated with sand, wood chips, particles of bark, and various other types of debris [8]. It is also unstable in its chemical composition, so that from the time it emanates from the tree undergoes various chemical changes. This crude material is usually subjected to heating in a fire still, thereby driving off the volatile components which are condensed as gum spirits of turpentine. The remainder in the still contains gum rosins which can be used as desired. 


\section{Properties of Rosin}

Methods for improving rosin production and its properties. Rosin acids are the non-volatile components of the pine resins [9] and chemically contain fused ring system. However, they also possess anti-aromatic characteristics which make them conducive to reaction under mild conditions. Rosin acids can undergo isomerisation at elevated temperatures and interchange the form of levopimaric acid (Figure 4) that is subjected to Diels-Alder addition (Figure 5) [10] which can be used as a rigid building block in the main chain of aliphatic polyesters to manipulate their mechanical properties and crystallisation behaviours. The modified rosin provides different softening points and acid values that is used for various applications (Table 1).<smiles>[2H][C@]12CCC[C@@](C)(C(=O)O)[C@@]1(C)CCC1=CC(C(C)C)=CC[C@@]12C</smiles>

Fig. 4: Structure of a rosin acid isomer - levopimaric acid
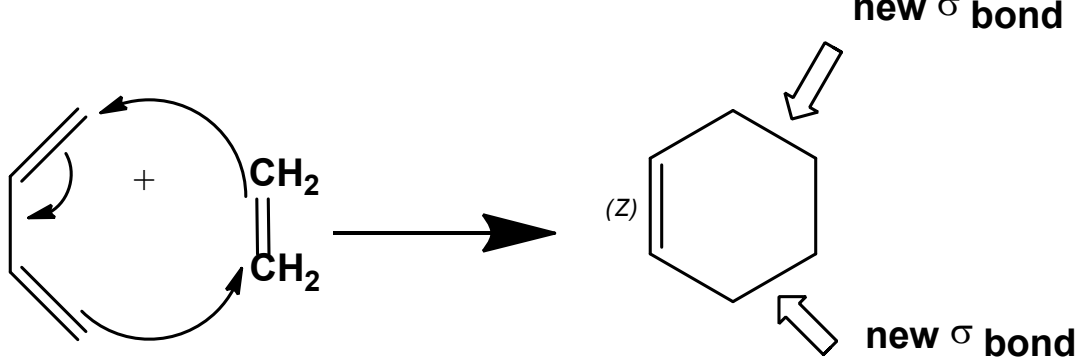

\section{Diene Dienophile}

Fig. 5: Diels-Alder reaction

Table 1: Physical properties of rosin and rosin derived esters for recommended application (RefRespol Resinas, S.A. Portugal)

\begin{tabular}{|l|l|l|l|l|l|}
\hline $\begin{array}{l}\text { Product } \\
\text { name }\end{array}$ & Product & $\begin{array}{l}\text { Acid Value } \\
(\mathrm{mg} \mathrm{KOH} / \mathrm{g})\end{array}$ & $\begin{array}{l}\text { Softening } \\
\text { Point }\left({ }^{\mathrm{O}} \mathrm{C}\right)\end{array}$ & $\begin{array}{l}\text { Colour } \\
(50 \% \\
\text { toluene })\end{array}$ & $\begin{array}{l}\text { Properties and application } \\
\text { recommendations }\end{array}$ \\
\hline $\begin{array}{l}\text { POLIMELT } \\
\text { Tall oil } \\
\text { rosin ester }\end{array}$ & P 88 & $\leq 10$ & $80-90$ & $\leq 4$ & $\begin{array}{l}\text { Light and stable glycerol rosin } \\
\text { ester recommended for hot } \\
\text { melt adhesives. }\end{array}$ \\
\hline & $\mathrm{P} \mathrm{90}$ & $\leq 6$ & $85-92$ & $\leq 4$ & $\begin{array}{l}\text { Highly stable glycerol rosin } \\
\text { ester with medium softening } \\
\text { point, ideal for pressure } \\
\text { sensitive adhesives. }\end{array}$ \\
\hline & P 98 & $\leq 10$ & $95-100$ & $\leq 4$ & $\begin{array}{l}\text { Light and stable pentaerythritol } \\
\text { rosin esters with low odour. } \\
\text { Recommended for hot melt } \\
\text { adhesives for packaging, } \\
\text { bookbinding and pressure } \\
\text { sensitive. }\end{array}$ \\
\hline
\end{tabular}




\begin{tabular}{|c|c|c|c|c|c|}
\hline & P 105 & $\leq 10$ & $102-108$ & $\leq 3$ & $\begin{array}{l}\text { High softening point } \\
\text { pentaerythritol rosin ester with } \\
\text { improved heat stability. }\end{array}$ \\
\hline & P 115 & $\leq 10$ & $112-117$ & $\leq 6$ & $\begin{array}{l}\text { Very high softening point } \\
\text { pentaerythritol rosin ester with } \\
\text { very low odour and volatility. }\end{array}$ \\
\hline & P 120 & $\leq 20$ & $114-120$ & $\leq 6$ & $\begin{array}{l}\text { Pentaerythritol rosin ester with } \\
\text { high softening point and high } \\
\text { heat resistance. }\end{array}$ \\
\hline & P 6302 & $80-90$ & $80-90$ & $\leq 4$ & $\begin{array}{l}\text { High acid value and medium } \\
\text { softening point glycerol rosin } \\
\text { ester designed for specialty } \\
\text { packaging hot melt adhesives. }\end{array}$ \\
\hline \multirow[t]{3}{*}{$\begin{array}{l}\text { TERGUM } \\
\text { Gum rosin } \\
\text { ester }\end{array}$} & T 103 & $\leq 20$ & 98-105 & $\begin{array}{l}\leq 5 \\
\leq 5\end{array}$ & $\begin{array}{l}\text { Pentaerythritol rosin esters } \\
\text { with excellent stability. } \\
\text { Recommended for hot melt } \\
\text { adhesives for packaging, } \\
\text { bookbinding and pressure } \\
\text { sensitive. }\end{array}$ \\
\hline & T 120 & $\leq 15$ & $114-120$ & $\leq 6$ & $\begin{array}{l}\text { Pentaerythritol rosin ester with } \\
\text { high softening point and high } \\
\text { heat resistance. Recommended } \\
\text { for hot melt adhesives. }\end{array}$ \\
\hline & Т 390 & $\leq 10$ & $85-91$ & $\leq 5$ & $\begin{array}{l}\text { Glycerol rosin ester for hot } \\
\text { melt adhesives with increased } \\
\text { tack requirements. } \\
\text { Recommended for packaging } \\
\text { and flooring adhesives and } \\
\text { depilatory waxes. }\end{array}$ \\
\hline $\begin{array}{l}\text { Tergum } \\
\text { Non- } \\
\text { crystallising } \\
\text { gum rosin }\end{array}$ & Т 19 & $135-155$ & $85-95$ & $\leq 8$ & $\begin{array}{l}\text { Non-crystallising gum rosin } \\
\text { with low volatile content. Ideal } \\
\text { for flooring adhesives and } \\
\text { pressure sensitive adhesives. }\end{array}$ \\
\hline Gum rosin & $\begin{array}{l}\text { Gum } \\
\text { rosin }\end{array}$ & $162-182$ & $72-87$ & $\leq 8$ & $\begin{array}{l}\text { Recommended as tackifier for } \\
\text { use in adhesive, varnishes, inks } \\
\text { and raw material for modified } \\
\text { resins. }\end{array}$ \\
\hline
\end{tabular}

Rosin acids in the synthesis of curing agents. Rosin-derived acids containing different functional groups are synthesised and studied for curing of epoxies. Liu et al have compared the dynamic mechanical properties and thermal stability of the epoxies cured by rosin-based curing agents and their petrochemical equivalents and discerned former exhibited similar curing reactivity and curing temperatures as their petroleum-based analogues. Wang et al have improved the flexibility of the cured epoxies by manipulating a flexible spacer between two terminal maleopimarate entities of the rosin-based anhydride curing agents. The introduction of the bulky phenanthrene-type rosin-derived anhydride ring into an epoxy or curing agent molecule result in the increase in glass transition $(\mathrm{Tg})$ and modulus but lower the thermal stability. The majority of them are cyclic which are either aromatic or cycloaliphatic anhydrides that impart high mechanical and physical properties toward the cured resins but low toughness, whereas aliphatic dicarboxylic acid anhydrides bring improved toughness. However, similarly the thermal stability of epoxy cured with rosin-based curing agents is improved greatly by the introduction of the imide units in the molecule of the curing agent. This is indicative of rosin-derived diacid containing imide structure potentially for feedstock material as an alternative to the petroleum use. 
Rosin-based epoxy binders. Structurally rosin acid molecules contain a hydrophobic skeleton and in blending with hydrophilic carboxylic group it can be utilised for various modifications leading to many coating applications. The direct application of rosin into varnishes for coating would be inept due to lack of appropriate binding properties hence requires treatment. Epoxy resin-based paints usually offer great corrosion protection properties and are widely used for different applications [11]. Limed rosin, ester gum, maleic modified rosin, rosin modified phenolic resins are some of the most important types of chemically upgraded rosins and a variety of treated rosins obtained by hydrogenation, polymerisation and disproportionation [12.13]. Rosin maleic anhydride adduct has been reported as a curing agent for epoxy resin [14]. Polypropylene glycol or polyoxy propylene diamine is heated with rosin and maleic anhydride at 3000C to obtain an abietic acid-levopimaric acid-maleic anhydride-polypropylene glycol/polyoxypropylene diamine copolymer containing terminal anhydride groups for use as a plasticizer and crosslinking agent for epoxy resin.

Modified rosin epoxy binders such as vinyl ester resins have been recognised as materials with excellent resistance to a wide variety of chemical conditions and can be used to fabricate a variety of reinforced constructions, e.g. pipes, tanks, scrubbers and ducts [15,16,17.18.19]. Moreover, these ester resins have also been used for coatings, adhesives, moulding compounds, structural laminates, electrical applications and for military and aerospace applications. Atta et al have prepared vinyl ester resin from rosin adducts using rosin acids as the diene and maleic anhydride or acrylic acid as the dienophile, these adducts produced maleopimaric acid and acrylopimaric acid (Figure 6) that are used to prepare vinyl ester resins. Maleopimaric acid and acrylopimaric acid are reacted with ethylene glycol followed by reaction with epicholorohydrine in the presence of sodium hydroxide as a catalyst to produce epoxy resins [20,21]. Schulze and workers have modified unsaturated polyesters by polyethylene glycol end groups to influence the solution behaviour in styrene and to modify the mechanical properties of the cured resin [22].
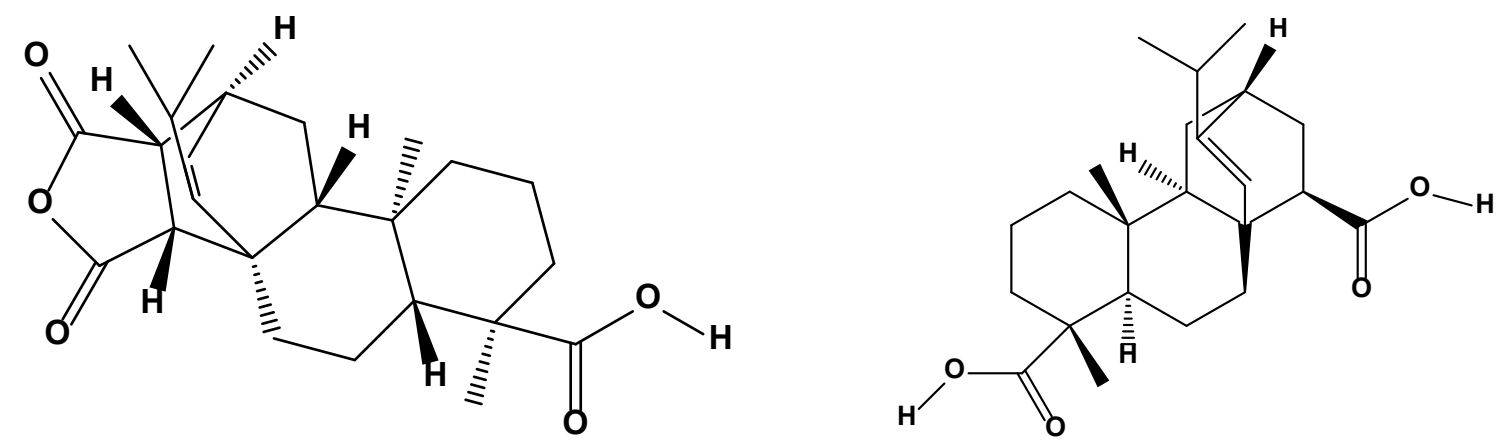

Fig. 6: Maleopimaric acid and acrylopimaric acid

Terminal unsaturated carboxylic polyester has been reacted with various polyethylene glycol monomethyl ethers of the molecular weights of 350-2000 g/mol to synthesise block copolymers which can be diluted in styrene to create curable resins, thus the conversion of polar end groups to polyethylene glycol end groups leading to improved flexibility of the cured material. Moreover, it has been reported the intermolecular chain interactions would also change and instead of hydrogen bonds, van der Waals interactions are prominent. Studies of poly(amide-imide) based on Diels-Alder adducts of rosin acid and its ketone with both maleic anhydride and acrylic acid have been reported [23.24]. The data for the mechanical properties (adhesion, impact strength, bending and hardness) of cured epoxy resins are indicative of having enhanced adhesive properties with steel on all cured epoxy resins based on abietic acid with polyamides. This may be due to high epoxy functionality of the resins and the presence of the terminal glycol groups as indicated by the hydroxyl numbers of the prepared epoxy binders based on abietic acid and its ketone.

\section{Rosin Based Composites}

Rosin is used to obtain new polymers such as polyesterimides [25] and polyamidimide [26]. It is also incorporated in some formulations of unsaturated polyester, but in small quantities [27]. A large 
majority of organic coating films in the end-use state exist in the form of a three-dimensional polymer network. Rosin and its derivatives are important chemicals in antifouling paint formulations. They may be used either as the vehicle or as the antifouling agent [28]. Unsaturated polyester (UP) resins are obtained by reacting the propylene (PG) or ethylene glycol (EG) with different acrylopimaric adducts (APA), maleic anhydride as a source of double bond, phthalic anhydride and adipic acid as dibasic acids. The molecular weights of UP are determined by end group analysis. The chemical structures of the resulting UP resins are confirmed by ${ }^{1} \mathrm{H}$ NMR analysis. The curing exothermic of UP, vinyl ester resins (VE) and styrene are evaluated at temperatures from 35 to $55^{\circ} \mathrm{C}$ using free radical initiator and accelerator. The curing behaviours of cured UP resins with styrene are evaluated by differential scanning calorimetry (DSC) measurements. The prepared UP curable resins are evaluated in the field of steel coating by measuring their mechanical properties and chemical resistance [29].

Polyacrylate/polymerized rosin composite emulsions have been reported [30] by Pingxu et al via seeded semi-continuous emulsion polymerisation of acrylate monomers in which polymerized rosin was dissolved. The effects of polymerized rosin content on the polymerization stability, monomer conversion, polymer structure, and adhesive properties are studied. Polyacrylate/polymerised rosin composites are characterized by gel permeation chromatograph (GPC), Fourier transform infrared spectroscopy (FTIR), differential scanning calorimetry (DSC) and thermogravimetry (TG). The results showed that with an increase of polymerised rosin content from 0 to $6 \mathrm{wt} \%$, gel fraction and sol molecular weight decreased but the monomer conversion remained unchanged. In contrast, with a further increase of polymerised rosin content, the decreasing rates of gel fraction, and sol molecular weight are slowed down, and the monomer conversion decreased remarkably. Moreover, interface failure changed into cohesive failure after the addition of polymerised rosin and the peel adhesion and shear resistance of composite latex films declined with the increase of polymerised rosin content. Thermal analysis showed that polymerised rosin and polyacrylate are compatible and the composite latex films had good thermal stability.

Hydrogenated rosin epoxy methacrylate (HREM) based on hydrogenated rosin and glycidyl methacrylate (GMA) have been synthesised as an advanced tackifier in the UV-crosslinking pressure sensitive adhesives (PSAs) system [31]. The HREM as a tackifier contained UV-curing sites, thus allowed photo-polymerization to occur by UV irradiation. This UV-curable tackifier, HREM, can improve the curing rates and adhesion performance of UV-crosslinking PSAs. The characteristics of HREM are subsequently analyzed by GPC and DSC and its synthetic mechanism studied using FTIR and $1 \mathrm{H}$ NMR, the characteristic peaks of hydrogenated rosin and GMA vanished, but new peaks for HREM appeared. The Polydispersity Index (PDI) and the Tg by DSC were 1 and $25.6^{\circ} \mathrm{C}$ respectively. The photo-polymerization of HREM is studied using photo-DSC. Heat flow observed during UV irradiation, the curing rate and conversion both are increased with rising photo-initiator content.

Coal-tar pitch is a complex material constituted of aromatic compounds with different functionalities and a broad molecular weight distribution. It is an excellent binding material in production of carbon materials or carbon-carbon composites [32]. Coal-tar pitch is modified with rosin and carbonisation behaviour of the modified pitches and optical texture of resultant semi-cokes have been reported in this paper [33]. The carbonisation behaviour is studied by thermogravimetric analysis (TGA) and Fourier transform infrared (FTIR) spectroscopic techniques. The optical texture of resultant semi-cokes is characterised by polarised-light microscopy. The results show marked differences in the carbonisation behaviour of coal-tar pitch and the modified pitches. The modification results in a small decrease in carbonisation yield by $1.2-3.2 \%$ when rosin content is kept at $5-15 \mathrm{wt} \%$ of coal-tar pitch. The modified pitches have functional groups of cyclo paraffin, double bonds and carboxyl group which gradually disappear, and aromatisation degree increases with increasing heat treatment. Moreover, the modification contributes to a notable improvement in the optical texture of resultant semi-cokes which varies from coarse-grained mosaics to domains.

PSAs are of interest because of their inherent tackiness, which allows them to quickly wet and adhere under a light pressure on a broad variety of substrates [34]. The first generation of PSAs was elaborated by blending natural rubbers with low-molecular-weight, miscible additives in 
approximately equal proportions [35]. Nowadays, most PSA's are synthetic, viscoelastic materials based on styrenic block copolymers (SBC), acrylic copolymers or silicone elastomers [36]. With the goal of developing new PSA systems, the miscibility and the phase morphology of blends between novel symmetric four-arm star "all-acrylate" block copolymers synthesised by atom transfer radical polymerisation (ATRP) and a rosin ester resin tackifier has been studied with a combined DSC and atomic force microscopy (AFM) approach [37]. Copolymer-resin compositions with increasing resin content in the blend were studied. The DSC results have shown good miscibility for compositions lower than $60 \mathrm{wt} \%$, with a single glass transition at a temperature between those of the two pure compounds. The AFM results indicate the initial two-phase morphology typical of the block copolymer matrix is preserved up to $60 \mathrm{wt} \%$ of resin. Above that value, a third phase, attributed to aggregates of the pure resin is observed. Upon ageing, the homogeneous systems (e.g., blends with $40 \mathrm{wt} \%$ of resin) undergo a slow migration of the tackifying resin towards the surface of the sample, which can be understood in terms of surface free energy considerations. This eventually leads to the formation of a layer of pure resin at the surface.

In the past decades, polyacrylate emulsions-based PSAs have been widely used in building, electron and wiring, automobile, packing, and daily life, because of some advantages such as freepollution, low cost, simple process and easy controllable viscosity, and so forth [38,39,40,41]. Hydrogenated rosin (HR)/polyacrylate composite mini emulsions-based pressure sensitive adhesives are synthesised by in situ mini emulsion polymerisation method [42]. The effect of HR amount on the monomer conversion rate, particle size and its polydispersity, coagulum rate, Zeta potential, and stability of the composite mini emulsions have been studied, the effect of HR and cross-linker amount on the adhesion properties of the composite latex films have also been investigated, and the composites are characterised by DSC and gel permeation chromatograph (GPC). The results show that with HR amount increasing, the monomer conversion rate decreased, and the absolute value of Zeta potential and the molecular weight of the sol in the composite latex films also decreased, while the particle size and its polydispersity are almost unaffected. DSC analysis indicated that HR had relatively good compatibility with polyacrylate. However, excess HR amount leads to the decrease of the centrifugal stability and storage stability of the composite mini emulsions. Furthermore, with HR amount increasing, the ball tack of the latex films increases gradually, 180o peel strength first increases and then decreases and holding force decreases constantly. When HR exceeds $10 \mathrm{wt} \%$, the failure style changes from interface failure to cohesion failure. The cross-linker CX-100 (a polyfunctional aziridine liquid cross-linker) is helpful for the improvement of $180 \mathrm{o}$ peel strength and holding force. When HR and CX-100 amount are 10 and $0.6 \mathrm{wt} \%$, the ball tack, 180 o peel strength, and holding force are $9,8.9 \mathrm{~N} / 25 \mathrm{~mm}$, and $178 \mathrm{~h}$, respectively.

A novel pathway for preparation of biomass-based waterborne polyurethanes (WPU) with excellent properties from cellulose and rosin has been discussed [43]. In this study, cellulose nanocrystals (CNs) are used as nano-fillers to improve properties of rosin-based waterborne polyurethanes (RWPU). The morphology, structure, thermal, and mechanical properties of the RWPU/CNs nano-composites are investigated. It demonstrates that CNs are compatible with RWPU and disperses homogeneously in the polymer matrix. CNs as nano-fillers improve tensile strength of RWPU significantly. Tensile strength of RWPU/CNs composite films increases from 28.2 to 52.3 $\mathrm{MPa}$ with increasing CNs amount from 0 to $20 \mathrm{wt} \%$. Moreover, the thermal stability of RWPU is also improved by CNs and the glass transition temperature of RWPU/CNs decreases comparing with RWPU.

Rosin and beeswax are two complex natural materials presenting numerous applications in paints, adhesives, varnishes or inks. Melted, they are particularly interesting for their adhesion properties. This paper [44] establishes the first phase diagram beeswax/rosin blends. A systematic approach using X-ray diffraction (XRD), DSC and polarised optical microscopy (POM) have been performed to describe the crystallographic structure and the thermal properties of two materials, beeswax and rosin, and their blends. Softening and crystallisation temperatures, polymorphic transitions and crystalline index have also been investigated. The resulting phase diagram reveals a complex 
behaviour in terms of phase transformation and time-dependent phenomenon mainly representative of the complex composition of beeswax.

A preparation of liquid thermal stabiliser (LTS) has been reported [45] using rosin and fatty acids as feedstock and evaluates for its stabilising effects on poly (vinyl chloride) (PVC). First, a rosin/oilbased dimer acid (RODA) is prepared by the addition reaction of rosin and industrial fatty acids and then converted into its zinc soap (RODA-Zn) and calcium soap (RODA-Ca). The chemical structures are inspected by UV-Vis and Fourier Transform infrared spectroscopies. Liquid form thermal stabilisers (RODA-LTS) are obtained by treating the solid RODA-Zn and RODA-Ca soaps with epoxidized soybean oil, triphenyl phosphite and liquid paraffin at $120 \mathrm{oC}$ for $3 \mathrm{~h}$. Thermal stabilising effects of the resulting RODA-LTS for PVC are compared with that of two commercial LTSs. Thermal stability of PVC compounds is determined using dehydrochlorination test, TGA, Congo red test and torque rheological analysis. Results indicate that RODA-LTS have overall superior thermal stability. Tensile and dynamic mechanical properties of the PVC compounds are also studied, and the results indicated that the PVC compounds stabilised with RODA-LTS and commercial LTSs displaying comparable strength, modulus and glass transition temperatures.

The enzymatic synthesis of rosin acid starch is reported [46] by esterifying cassava starch with rosin acid directly using dimethyl sulphoxide (DMSO) as the solvent. Response surface methodology (RSM) based on a three-factor-three-level Box-Behnken central composite design is applied to evaluate the effects of synthesis conditions, namely reaction temperature, reaction time and enzyme amount. The optimal condition for achieving high degree of substitution (DS) of the esterified product is reaction time $4.11 \mathrm{~h}$, temperature $48.18^{\circ} \mathrm{C}$, immobilised catalyst dosage $15.47 \%$ (by weight of starch), and a molar ratio of rosin acid/anhydrous glucose unit 2:1. The experimental DS value of 0.106 matches well with the predicted value of 0.11 . The structural changes between native starch and rosin acid starch are investigated by FTIR and Scanning electron microscopy (SEM).

Cassava starch is esterified with rosin acid [47] by using lipase as catalyst. The physicochemical properties of esterified starches with degree of substitution (DS) ranging from 0.031 to 0.092 are compared with native starch. Esterification of cassava starch is confirmed by FTIR spectroscopy. The results of SEM and XRD analysis reveal the morphology and crystallinity of the cassava starch are largely destroyed, and the esterification took place in both the non-stereotyped area and inside the crystalline regions of starch. TGA indicates that thermal stability of rosin acid starch decreases compared with native starch. Rosin acid starch exhibits higher viscosity as well as emulsifying properties. Esterified starch decreases its swelling power, solubility and transparency in water. Rosin acid starch has potential applications in food and biomedical materials.

A rosin-derived diacid and a dimer fatty acid are converted into diglycidyl ester type epoxies [48], respectively, and the chemical structures of the products are confirmed by 1H NMR, FTIR and Electrospray Ionisation-Mass Spectrometry (ESI-MS). A novel modification is introduced to the twostep synthesis of diglycidyl ester by using calcium oxide $(\mathrm{CaO})$ as water scavenger in the dehydrohalogenation step. Nadic methyl anhydride (Figure 7) is used as curing agent to cure these two bio-based epoxies and their mixtures in different weight ratios. The cure behaviour is studied using DSC. Flexural and dynamic mechanical properties of the cured resins are determined using three-point bending test and dynamic mechanical analysis (DMA). Thermal degradation of the cured resins is examined using TGA. Results suggest that the rigid rosin-derived epoxy and the flexible dimer acid-derived are complementary in many properties and the combination of them could result in resins with properly balanced properties and overall improved performance. 


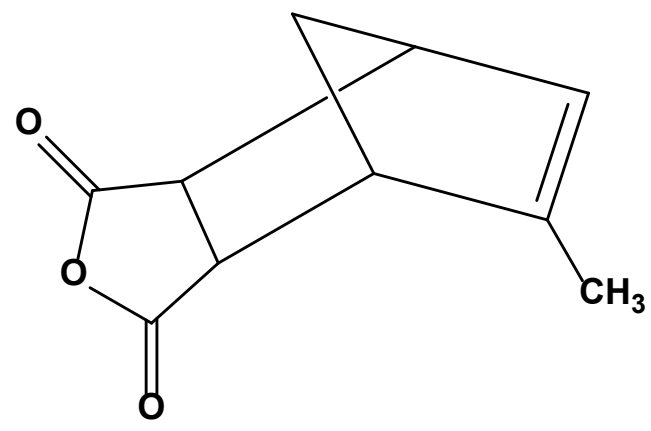

Fig. 7: Nadic methyl anhydride

Electrospinning. Electrospinning is a cheap, convenient yet versatile technology to obtain micro to nano scale fibres using an electric charge for various applications. Electrospun rosin fibres have hitherto not been reported to our knowledge; however, some studies have been reported with certain modifications.

The influence of antimicrobial additives on the formation of rosin fibres by using electrospinning technique has been reported [49]. Systematic experiments are performed to fabricate the rosin fibres via electrospinning and to reduce the size of the fibres by mixing some additives such as triethylbenzylammonium chloride (TEBAC), chitosan and silver nitrate in the rosin polymer solution. The morphology, structure and thermal properties of the electrospun rosin fibres are characterised by using SEM, XRD, FTIR, UV-Vis and TGA techniques. Rosin fibres with a diameter of the order of nanoscale are achieved using TEBAC additive. TEBAC is usually considered as a phase-transfer catalyst in chemical reactions. The use of a surfactant in electrospinning is considered as a means to reduce the surface tension thus addition of TEBAC may serve a similar purpose on rosin. The antimicrobial activity of the resultant fibres is checked by the antimicrobial disc diffusion test. The rosin fibres have shown excellent antibacterial activity against the gram negative bacteria and feeble activity against the gram positive bacteria. The study demonstrates that the electro-spun rosin fibres can be utilised for potential antimicrobial products.

Foam making. The halogen-free flame retardant rosin-based rigid polyurethane foams (RPUF) have been reported based on renewable rosin polyester polyol [50], intumescent flame retardants (such as expandable graphite and melamine polyphosphate) and layered double hydroxide. The morphology, thermal conductivity, mechanical property, thermal stability, flame retardancy and fire behaviours of all RPUFs are comprehensively investigated. Furthermore, potential synergy between layered double hydroxide (LDH), expandable graphite (EG) and melamine polyphosphate (MPP) on fire behaviour of rosin-based RPUF has also been investigated in detail. XRD results showed that LDH is exfoliated and well dispersed in RPUF. The results of SEM and thermal conductivity tests show that adding intumescent flame retardants (such as EG and MPP) or further adding LDH into RPUF does not have significant influence on the cell structure and thermal conductivity of RPUF. The results of TGA show that adding EG, MPP or further adding LDH into RPUF decreases the initial decomposition temperature and the second-stage maximum-rate decomposition temperature of RPUF, while increases the char residue of RPUF at high temperature whether under N2 atmosphere or air atmosphere. Furthermore, it is noteworthy that simultaneously adding EG, MPP and LDH into RPUF can significantly improve the flame retardancy, mechanical property and fire behaviour of RPUF. The limiting oxygen index (LOI) value of EG10/MPP10/LDH3.0/RPUF sample increases from 19.1 to $28.0 \%$ compared with that of pure RPUF. The compressive strength and specific compressive strength (compressive strength/density) for EG10/MPP10/LDH3.0/RPUF sample in parallel direction increase about $8.3 \%$ and $7.1 \%$ compared with that of pure RPUF, respectively. The cone calorimeter test results show that simultaneously adding EG, MPP and LDH into RPUF can significantly decrease the heat release rate (HRR), total heat release (THR) and smoke emission behaviour of RPUF sample. The average heat release rate (Av-HRR) and THR decrease about 32.5\% and 5.2\% compared to that of pure RPUF, respectively. The average smoke production rate (AvSPR), average rate of smoke release (Av-RSR), average specific extinction area (Av-SEA), total 
smoke release (TSR) and CO/CO2 weight ratio of EG10/MPP10/LDH3.0/RPUF sample decrease about $26.9 \%, 25.5 \%, 2.7 \%, 0.8 \%$ and $16.7 \%$ compared with that of pure RPUF, respectively. These test results indicating that LDH has synergistic effect with intumescent flame retardants (such as EG and MPP) on improving the fire behaviour of rosin-based rigid polyurethane foam.

We have recently reported the formation of rosin foam (eco-foams) in a single-pot scheme via the use of an industrial foaming agent for potential thermal insulation [51]. The resulting eco-foams have been compared with urea formaldehyde foam insulation (UFFI) proved to be a better alternative with no harmful gas emission subsequent to foam making. This open cell foam making has shown a variety of porosity as depicted in the Figure 8 .

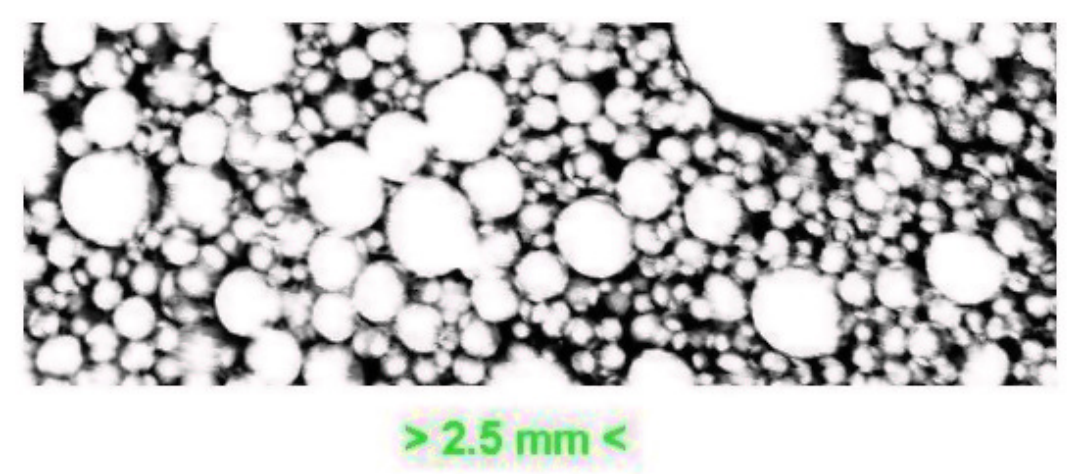

Fig. 8: The micro-computerised tomography of rosin foam [51]

\section{Applications of Rosin Based Composites}

Material Strength. Two rosin-based imide-diacids have been synthesised and studied as epoxy curing agents [52]. In comparison, a similar imide-diacid based on trimellitic anhydride (a polyamideimide plastic) has also been prepared. The chemical structures are confirmed by ${ }^{1} \mathrm{H}$ NMR and FTIR. The curing of a commercial epoxy with these imide-containing diacids is studied by differential scanning calorimetry (DSC). Thermal stability, tensile and dynamic mechanical properties of the cured epoxies is investigated. The results indicate that rosin-based imide-diacids used as curing agents resulted in significantly higher glass transition temperature, tensile and dynamic mechanical properties than the imide-diacid derived from trimellitic anhydride. Rosin acids have a great potential to replace some of the current petroleum-based compounds in the synthesis of epoxy curing agents.

Wood-flour is treated with maleic rosin to improve its flow behaviour [53], and then compounded with high density polyethylene (HDPE) by an extruder to prepare wood-flour/HDPE composite (WFHDPE). X-ray photoelectron spectroscopy (XPS) and FTIR spectroscopy techniques have been used to study the change in the functional group and element of wood flour before and after treatment. The rheological behaviour of the WF-HDPE composites is investigated by a rotary rheometer. XPS and FTIR spectroscopy analysis indicated that chemical bonds are formed between maleic rosin and wood flour through the esterification reaction of anhydride groups and hydroxyl groups on wood surface. Maleic rosin has been added to the surface of wood flour in the form of monoester, i.e., the formation of esterified wood flour bearing a pendent carboxylic group. The rheological study shows that the complex viscosity, storage modulus and loss modulus of WF-HDPE composites decrease firstly and increase afterward and decline lastly as the dosage of maleic rosin increases, however, the viscosity of the composite melts decreases. After the modification of wood flour, the rheological properties of composite melts are improved markedly. According to the mechanical test it is indicated that, by proper treatment of wood flour with maleic rosin, the tensile strength and flexural strength of WFHDPE increase obviously.

Composites for biomedical applications. Composite material use in biomedical applications has been of interest in recent times due to nano medicine and its influence in drug delivery of the human body thus cell interactions and adhesions. 
In dental studies remineralisation is stimulated by the super saturation of ions in the saliva, especially when the $\mathrm{pH}$ is greater than the critical $\mathrm{pH}$ and the mineral can precipitate [54]. When the $\mathrm{pH}$ drops below the critical $\mathrm{pH}$ the saliva is no longer saturated and the tooth will demineralise [55]. The control of phosphate ion release from ion permeable microcapsules formulated in to rosin varnish and resin glaze in dentistry has been reported [56]. The objective of this study is to investigate the most effective way to control the release rate of bio-available phosphate ions contained in aqueous solutions within ion permeable microcapsules formulated in to rosin based varnishes and resin based sealants, in order to promote remineralisation. Microcapsules that contained aqueous solutions of dipotassium phosphate (K2HPO4) with concentrations from 0.8 to $7.4 \mathrm{M}$ have been prepared. 3-50 $\mathrm{w} / \mathrm{w} \%$ of microcapsules were loaded into both rosin and resin based dental formulations. The effect of initial salt solution concentration inside the microcapsules and weight per cent loading of the microcapsules on release rate are contrasted. The effect of microcapsule loading is found to be highly dependent on the continuous phase. In rosin, 3-15 w/w\% loading results in rapid release of ions. Higher weight per cent loadings are initially slower but result in sustained release of ions. In resin, $3-15 \mathrm{w} / \mathrm{w} \%$ formulations slowly release ions for at least 300 days, while higher loading formulations release an initial burst of ions. Initial salt solution concentration contains inside the microcapsule affects ion release rate. Initial rate of ion release is greatest at a concentration that is less than the maximum concentration studied in both continuous phases. Phosphate ion release can be controlled from resin or rosin based dental material by adjusting initial salt solution concentration in microcapsules or per cent loading of microcapsules. The potential for burst release from a varnish or slow, sustained release from a sealant has been demonstrated. The paper demonstrates the ability to provide both a rapid release of ions, as well as the sustained long-term release of ions for remineralisation. This is done by studying the effect of the initial salt concentration within the microcapsule and the per cent loading of microcapsules into a rosin and resin dental formulation. Phosphate is critical for the process of remineralisation and has been confirmed that these ions are capable of diffusing from microcapsules loaded in either formulation which can be contributed to the prevention of primary and secondary caries.

\section{Other Rosin Applications}

Copper compounds have been used in wood preservative formulations for more than 200 years [57]. Among them, chromate copper arsenate (CCA) has high resistance to leaching and very good performance in service. Nevertheless, this conventional wood preservative has been banned for some applications due to its mammalian toxicity and its adverse effect on the environment [58]. Therefore, the present investigations are undertaken to develop fungicides that would not only effectively protect wood against biological corrosion but would also be characterised by lower leaching of the biologically active substance. The aim of this study is to determine the effect of rosin upon some physical and mechanical properties of poplar wood [59] treated with mixtures of 3\% CuSO4 and $1.0 \%, 2.0 \%$, or $4.0 \%$ rosin sizing agent. The new approach and reaction mechanisms between carboxylic acid groups of resin acids of rosin and copper have been investigated by Pizzi [60], and wood blocks treated with solutions of rosin-copper soap using benzene or ethanol as solvents have shown to be effective against both fungal and termite in field tests [61]. Rosin-copper treatments decrease the moisture absorption, water absorption (WA) and swelling properties of wood, whilst increasing water repellent efficiency and anti-swelling efficiency to approximately $40 \%$ after 30 -day immersion in water. In general, rosin-copper treatments increase the compression strength parallel to grain and Brinell hardness (BH) compared with controls, but the modulus of rupture (MOR) and modulus of elasticity (MOE) are lower than that of control. Some physical and mechanical properties of rosin-copper treated wood is examined. Rosin-copper treatment decreases the moisture absorption, WA and swelling of wood. Rosin-copper treatments improve dimensional stability of the wood considerably. Rosin-copper treatments also increase the compression strength parallel to grain (CSPG), BH on longitudinal and radial surface. MOR, MOE and $\mathrm{BH}$ on tangential values are slightly lower than that of control. 


\section{Future Prospects}

Rosin is a versatile material for potentially many different industrial applications across the board making it a notable starting material for research purposes. Its value as a natural material has already been exploited for several years in many established industries. Both science and technology have channelled routes to improve its value to the point that can be used for advanced applications thus as a value-added material. For an example polymerisation has been discussed in research as a potential pathway to improve the mechanical properties. However, the degree of polymerisation has been reported as very limited. It has also been used as a composite material to improve the viscoelastic properties. Rosin as an eco-material can be targeted for construction, for an example as thermal insulation, foam making and in biomedical industry such as tissue engineering.

\section{Conclusion}

In this review paper we have looked at some of the recent developments pertaining to research based on rosin and its associate products. Rosin has been employed in numerous applications as a material to product development and potentially as a green route in science. Modified rosin is amongst the most established product lines discussed along with its chemical characteristics. The paper presents an overall view to disseminate rosin, its intrinsic characters, established applications in industry, research studies in dentistry and potential foam making.

\section{Acknowledgement}

This work is supported by the Fundação para a Ciência e a Tecnologia (FCT) and Centro2020 through the Project references: PAMI - ROTEIRO/0328/2013 ( $\mathrm{N}^{\circ}$ 022158) and MATIS (CENTRO01-0145-FEDER-000014 - 3362)

\section{References}

[1] J. Zhang, Book titled 'Rosin-based chemicals and polymers', Smithers Rapra, 2012.

[2] K. Fiebach, D. Grimm, (2000). "Resins, Natural". Ullmann's Encyclopedia of Industrial Chemistry.doi:10.1002/14356007.a23_073. ISBN 978-3-527-30673-2.

[3] S. Maiti, S. Das, M. Maiti and A. Ray, Polymer publications of renewable-Resource materials, Eds, C.E. Carraher and L. H. Sperling, Plenum press, NY, USA, 1983, p. 129.

[4] H. F. Enos, Current and potential use of Rosin, presented at Paper and Textile Chemistry Division Meeting, American Chemical Society, March 23, 1977, p. 75.

[5]Information on http://www.sust-forest.eu/sites/www.sustforest.eu/files/antonio_romero_luresa.pdf

[6] Information on https://rescoll.fr/blog/wp-content/uploads/2013/04/J.-Alcorta-La-industria-enEuropa.pdf

[7] FAO corporate document repository- Chapter 1 Production trade and markets, Description, uses and principal sources, http://www.fao.org/docrep/v6460e/v6460e05.htm

[8] A. Donald, A. Lister and G. Brunswick, Oleoresin treatment U.S. Patent 2340672. (1940)

[9] R. Ibrahim, L. Varin, V. De Luca, J. Romeo, Terpenoids in conifers, Evolution of Metabolic Pathways, Elsevier Science Ltd, 2000, p. 111.

[10] W. D. Lloyd, G. W. Hedrick, The Diels-Alder Reaction of Levopimaric Acid and Its Use in Quantitative Determinations, J. Org. Chem., 1961, 26 (6), pp. 2029-2032, DOI: 10.1021/jo01065a085.

[11] H. Uhlig, Corrosion and Corrosion control, John Wiley \& Sons, NY, USA, 1971. 
[12] H. I. Enos, G. C. Harris and G. W. Hedrick, Kirk-Othmer Encyclopaedia of Chemical Technology, 2nd Ed., A Standen, Interscience, NY, USA, 1968, 17, p. 475.

[13] W. D. Stonecipher and R. W. Turner in Encyclopaedia of Polymer Science and Technology, Ed., N M Bikales, Interscience, NY, USA, 1970, 12, p. 139.

[14] P Penczek, Polimery, 1975, 20, p. 371.

[15] S.S. Sonti and E.J. Barbero, Journal of Reinforced Plastics and Composites, 1996, 15, p. 701.

[16] N. Hag and P. Harrison, Corrosion Prevention and Control, 1996, 43, p. 162.

[17] K. Liao, R. I. Altkorn, S.M. Mikovich, J.M. Fildes, J. Gomez, C. R. Schultheisz, D. L. Hunston and L.C. Brinson, Journal of Advanced Materials, 1997, 28, p. 54.

[18] J. R. Brown and Z. Mathys, Composites, 1997, 28A, p. 675.

[19] U. Sorathia and T. Dapp, International SAMPE Symposium and Exhibition, 1997, 42, p. 1020.

[20] A. M. Atta, S. M. El-Saeed and R.K. Farag, Reactive and Functional Polymers, 66 (2006) pp. 1596-1608.

[21] A.M. Atta, I.F. Nassar and H.M. Bedawy, Reactive and Functional Polymers, 2007, 67, p. 617.

[22] U. Schulze, M. Skrifvars, N. Reichelt and H. Schimdt, Journal of Applied Polymer Science, 1997, 64, p. 527.

[23] A.M. Atta, R. Mansour, M.I. Abdou and A.M. El-Sayed, Journal of Polymer Research, 2005, 12, p. 127.

[24] A.M. Atta, R. Mansour, M.I. Abdou and A.M. Sayed, Polymers for Advanced Technology, 2004, 15, p. 514.

[25] R. Kay, N.L. Hancox (Ed.), Fiber Composite Hybrid Materials, Applied Science Publishers Ltd., London (1981), p. 142.

[26] S. Maiti, S. Das, Polym. Prepr., 21 (1980), p. 190.

[27] S. Maiti, A. Ray, M. Maiti, S. Das, Org. Coat. Plast. Chem. Prepr., 45 (1981), p. 449.

[28] V. Rascio, C.A. Giudice, J.C. Benitz, M. Presta, in: Bio. Mar. Comun. Congr. Int. Corr. Mur Incrustaciones, 5th, 1980, p. 321.

[29] A. M. Atta, A. M. Elsaeed, R. K. Farag, S. M. El-Saeed, Synthesis of unsaturated polyester resins based on rosin acrylic acid adduct for coating applications, Reactive \& Functional Polymers 67 (2007) pp. 549-563.

[30] P. Chen, X. Zeng, H. Li, X. Liu, D. Liu and X. Li, Journal of Applied Polymer Science, 124, 6 (2012), pp. 4694-4701.

[31] H. Do, J. Park, H. Kim, Synthesis and Characteristics of Photoactive-Hydrogenated, Rosin Epoxy Methacrylate for Pressure Sensitive Adhesives, J. App. Polym. Sci. 111, (2009), pp. 11721176.

[32] Q. Lin, T. Li, C. Zheng, Y. Zhao, S. Song, J. Anal. Appl. Pyrolysis, 71 (2004), pp. 817-826.

[33] Q. Lin, W. Su, Y. Xie, Effect of rosin to coal-tar pitch on carbonization behavior and optical texture of resultant semi-cokes, Journal of Analytical and Applied Pyrolysis, 86, 1, (2009), pp. 8-13.

[34] J. Mallegol, O. Dupont and JL Keddie. Langmuir 17, (2001), p. 7031.

[35] C. Creton, MRS Bull. 28, (2003), p. 434.

[36] I. Benedek, Pressure-sensitive adhesives and applications 2nd ed. New York: Dekker Marcel, 2004. 
[37] M. Jeusette, S. Peeterbroeck, F. Simal, D. Cossement, P. Roose, Ph. Leclère, Ph. Dubois, M. Hecq, R. Lazzaroni, Macromolecular Nanotechnology, Microscopic morphology of blends between a new "all-acrylate" radial block copolymer and a rosin ester resin for pressure sensitive adhesives European Polymer Journal 44 (2008) pp. 3931-3940.

[38] G.E. Fonseca, T.F. McKenna and M.A. Dubé, Influence of particle nucleation in pressure sensitive adhesive properties: mini emulsion versus emulsion polymerization. Macromol. Symp. 271, (2008), pp. 83-93.

[39] X. Jiang, H.L. Hu, Y.C. Bai, X.Z. Tian, D. Huang, S.G. Wang, Synthesis and properties of the vinyl silicone oil modified polyacrylate core-shell latex as a binder for pigment printing. J. Adhes. Sci. Technol. 27, (2013), pp. 154-164.

[40] L. Zhang, Y.J. Cao, L. Wang, L. Shao and Y.P. Bai, Synthesis and properties of soap-free P(2EHA-BA) emulsion for removable pressure sensitive adhesives. RSC Adv. 4, (2014), pp. 4770847713.

[41] H.Q. Li, Y. Zhong, X.J. Lai, P.X. Chen and X.R. Zeng, Effect of hydrogenated acrylic rosin on structure and properties of polyacrylates emulsions by seeded semibatch emulsion polymerization method. J. Adhes. Sci. Technol. 29 (2015), pp. 740-752.

[42] L. Hongqiang, L. Tao, L. Yanping, L. Xuejun, R. Xiaokang and Z. Xingrong, In situ synthesis and properties of hydrogenated rosin/polyacrylate composite miniemulsions-based pressure sensitive adhesives, Journal of Adhesion Science and Technology, 29 (2015), 20, pp. 2220-2232.

[43] H. Liua, S. Cui, S. Shanga, D. Wang and J. Song Properties of rosin-based waterborne polyurethanes/cellulose nanocrystals composites, Carbohydrate Polymers 96 (2013) pp. 510-515.

[44] Y. Gaillard, A. Mija, A. Burr, E. Darque-Ceretti, E. Felder and N. Sbirrazzuoli, Green material composites from renewable resources: Polymorphic transitions and phase diagram of beeswax/rosin resin, Thermochimica Acta., 521 (2011), pp. 90-97.

[45] M. Li, J. Jiang, J. Zhang, X. Yang, Y. Zhang, S. Li, J. Song, K. Huang, J. Xia, Polymer Degradation and Stability, 109 (2014), pp. 129-136.

[46] R. Lin, H. Li, H. Long, J. Su, W. Huang, S. Wang, Optimization of lipase-catalyzed rosin acid starch synthesis by response surface methodology, Journal of Molecular Catalysis B: Enzymatic, 105 (2014), pp. 104-110.

[47] R. Lin, H. Li, H. Long, J. Su, W. Huang, Structure and characteristics of lipase-catalyzed rosin acid starch, Food Hydrocolloids, 43 (2015), pp. 352-359.

[48] K. Huang, J. Zhang, M. Li, J. Xia, Y. Zhou, Exploration of the complementary properties of biobased epoxies derived from rosin diacid and dimer fatty acid for balanced performance, Industrial Crops and Products, 49 (2013), pp. 497-506.

[49] R. Nirmala, B. Woo-il, R. Navamathavan, D. Kalpana, Y. S. Lee, H. Y. Kim, Influence of antimicrobial additives on the formation of rosin nanofibers via Electrospinning, Colloids and Surfaces B: Biointerfaces 104 (2013), pp. 262-267.

[50] L. Gao, G. Zheng, Y. Zhou, L. Hu, G. Feng and Y. Xie, Synergistic effect of expandable graphite, melamine polyphosphate and layered double hydroxide on improving the fire behavior of rosin-based rigid polyurethane foam, Industrial Crops and Products, 50 (2013), pp. 638-647.

[51] V. Mahendra, G. R. Mitchell and A. Mateus, The Development of Rosins as Potential Eco-Foams from Pine Derived Resins, 5th International Conference on Biofoams, Sorrento, Italy, 13-16 October 2015.

[52] X. Liu, W. Xin, J. Zhang, Rosin-derived imide-diacids as epoxy curing agents for enhanced performance, Bioresource Technology, 101,7 (2010), pp. 2520-2524. 
[53] O. Rongxian, W. Q. Wen, Effects of maleic rosin on the rheological properties of wood flour/HDPE composites, Scientia Silvae Sinicae 45, 5 (2009), pp. 126-131.

[54] C. Dawes, What is the critical $\mathrm{pH}$ and why does a tooth dissolve in acid? Journal of Canadian Dental Association 69, 11(2003), pp. 722-724.

[55] T. Aoba, Solubility properties of human tooth mineral and pathogenesis of dental caries. Oral Diseases, 10, (2004), pp. 249-57.

[56] M. M. Falbo, P. Elassal, T. A. Greving, W. A. McHale, M. A. Latta, S. M. Gross, The control of phosphate ion release from ion permeable microcapsules formulated in to rosin varnish and resin glaze, dental materials 29 (2013), pp. 804-813.

[57] N.T.B. Ngoc, Wood preservation, Agriculture Press, Ha Noi (2006) [in Vietnamese].

[58] T. Townsend, H. Solo-Gabriele, Environmental impacts of treated wood, CRC Boca Raton, Florida (USA) (2006).

[59] T. T. H. Nguyen, S. Li, J. Li, The combined effects of copper sulfate and rosin sizing agent treatment on some physical and mechanical properties of poplar wood, Construction and Building Materials 40, (2013), pp. 33-39.

[60] A. Pizzi, A new approach to nontoxic, wide-spectrum, ground-contact wood preservatives. 1. Approach and reaction mechanisms, Holzforsch, 47 (3) (1993), pp. 253-260.

[61] A. Pizzi, A new approach to nontoxic, wide-spectrum, ground-contact wood preservatives. 2. Accelerated and long-term field tests, Holzforsch, 47 (4) (1993), pp. 343-348.

[62] Excerpted from the Respol Resinas, S.A. Portugal, 2017. 